\title{
Ultrastructural localization of carbonic anhydrase in gastric parietal cells with the immunoglobulin-enzyme bridge method
}

\author{
AKIRA SATO ${ }^{1}$, SAMUEL S. SPICER ${ }^{1}$ and RICHARD E. TASHIAN ${ }^{2}$ \\ ${ }^{1}$ Department of Pathology, Medical University of South Carolina, Charleston, South Carolina 29403, \\ U.S.A. \\ ${ }^{2}$ Department of Human Genetics, University of Michigan Medical School, Ann Arbor, Michigan 48109, \\ U.S.A.
}

Received 10 April 1980 and in revised form 11 July 1980

\section{Summary}

Ultrastructural immunostaining of carbonic anhydrase in gastric parietal cells was accomplished with the immunoglobulin-peroxidase bridge procedure applied to cryostat sections of fixed guinea-pig stomach prior to dehydration and embedment. Of a variety of fixatives tested, only freshly prepared paraformaldehyde buffered with calcium acetate provided both immunostaining and adequate preservation of ultrastructural morphology. Delipidization or exposure of specimens to detergent prior to staining enhanced the intensity of the immunostaining and increased the sensitivity of the method. Increased diaminobenzidine concentration in the peroxidase substrate appeared also to intensify the densification at the reactive site. Carbonic anhydrase was localized ultrastructurally with this pre-embedment immunobridge procedure in the hyaloplasm of gastric parietal cells and less consistently in the superficial surface epithelium. The basal portion of the parietal cells stained more intensely than the apical region and immunoreactivity appeared concentrated at the plasmalemma and around mitochondria.

\section{Introduction}

The ultrastructural localization of carbonic anhydrase (carbonate dehydratase, EC 4.2.1.1) in gastric epithelium has been investigated (Cross, 1970; Winborn et al., 1974) with cytochemical cobalt-bicarbonate technique in Häussler (1958) or its modification by Hansson (1967) or Yokota (1969). However, sites of localization of carbonic anhydrase activity by this method varied on incubation with different substrate media (Cross, 1970; Winborn et al., 1974), thus raising questions about the validity of these cytochemical methods (Churg, 1973; Muther, 1977).

Carbonic anhydrase (CA) has also been localized cytochemically at the light 
microscopical level by an immunoglobulin-peroxidase bridge method (Spicer et al., 1979) which is not subject to the enzyme specificity problems of concern with the cobalt capture technique. The immunoperoxidase method has been utilized extensively to localize a variety of tissue antigens by light microscopy (Mason et al., 1969; Phifer et al., 1974; Spicer et al., 1977), but its application at the electron microscopic level has been limited because of problems with intracellular penetration of reagents and with fixing tissues sufficiently to preserve the fine structural morphology without loss of the immunoreactivity of the antigen (Spicer et al., 1977). The present report describes efforts to surmount these problems and demonstrate carbonic anhydrase in parietal cells by immunostaining at the ultrastructural level.

\section{Materials and methods}

Gastric corpus was obtained from anaesthetized albino guinea-pigs. A portion of the specimens was minced into blocks less than $1 \mathrm{~mm}^{3}$ with a razor blade and fixed for $1 \mathrm{~h}$ at $4^{\circ} \mathrm{C}$ in one of the following solutions: freshly prepared $4 \%$ paraformaldehyde buffered with either $2 \%$ calcium acetate or $0.1 \mathrm{M}$ sodium cacodylate $(\mathrm{pH} 7.2), 1 \%$ glutaraldehyde in $0.1 \mathrm{M}$ cacodylate buffer ( $\mathrm{pH} 7.2$ ), modified Karnovsky's fluid with a final concentration of $0.5 \%$ glutaraldehyde and $4 \%$ formaldehyde, or Carnoy's fluid. Specimens were rinsed for several hours in phosphate-buffered saline (PBS) and stored overnight at $4^{\circ} \mathrm{C}$ in PBS or in $70 \%$ ethanol to delipidize the tissues. Cryostat sections of $5 \mu \mathrm{m}$ thickness, as estimated by the cryomicrotome setting, were prepared from the fixed specimens at $-20^{\circ} \mathrm{C}$ and thawed in PBS. Prior to the immunostaining, some sections were treated for $15 \mathrm{~min}$ with a wetting agent, 1\% Laboratory Aerosol (this Fisher Scientific Co. commercial preparation, also designated Aerosol OT, contains dioctyl sodium sulphosuccinate and a solvent), and rinsed for $15 \mathrm{~min}$ in each of three changes of PBS.

The pre-embedment immunoglobulin-peroxidase bridge technique employed in this study resembled closely that described in preceding reports (Mason et al., 1969; Spicer et al., 1977; Spicer et al., 1979). The cryostat sections were exposed for 30-60 min to a 1:20 dilution in PBS of the primary rabbit antiserum to either carbonic anhydrase I (CA I) or carbonic anhydrase II (CA II). This was followed by a $30 \mathrm{~min}$ treatment with a 1:20 dilution of goat anti-rabbit immunoglobulin and a subsequent $30 \mathrm{~min}$ exposure to a 1:20 dilution of rabbit anti-peroxidase prior to application of a $0.5 \mathrm{mg} \%$ horseradish peroxidase (Sigma, St. Louis, Missouri) solution in PBS. Between steps the sections were drained and blotted free of excess reagent and washed for $30 \mathrm{~min}$ in PBS. The primary rabbit antiserum to human CA was prepared and characterized for specificity as described previously (Spicer et al., 1979). Control sections were prepared by substituting normal rabbit serum for the anti CA serum as the first component of the immuno-peroxidase bridge. To visualize the peroxidase activity, specimens were incubated for $10 \mathrm{~min}$ at room temperature in either standard Graham \& Karnovsky's (1966) medium or this substrate solution modified to contain $70 \mathrm{mg} \%$ of $3,3^{\prime}$-diaminobenzidine (DAB). After a rinse and post-fixation for $1 \mathrm{~h}$ in $1 \%$ osmium tetroxide, the sections were routinely dehydrated through graded ethanols and embedded in Epon. Ultrathin sections without heavy metal staining were viewed in a Hitachi HS-8 electron microscope. The photocell governing exposure of image plates in the electron microscope controlled the exposure to electrons rather than exposure time and, thereby, tended to diminish the obviously increased electron opacity in sections stained with the immunoglobulin-peroxidase bridge method. This was compensated for by exposing the prints so that empty appearing areas in the connective tissue or Epon 
beyond the edge of the tissue appeared equally dense in micrographs of comparably thick, immunostained and control sections.

Carbonic anhydrase was also localized immunohistochemically by light microscopy in paraffin sections of gastric epithelium fixed with a battery of fixatives (Spicer et al., 1979).

\section{Results}

Densification demonstrative of carbonic anhydrase (CA) was found selectively localized to the gastric parietal cells at the electron microscopic level. Antisera to the isozymes CA I and CA II immunostained the parietal cells similarly. The intensity of the immunoreactivity and the morphological integrity of the cells varied with different fixatives. Among those employed, freshly-prepared 4\% paraformaldehyde in $2 \%$ calcium acetate proved optimal in providing densification at the antigenic site and sufficient preservation of ultrastructure.

The intensity of immunostaining was also enhanced by various pre-embedment treatments which included delipidizing sections or treating them with detergent, and increasing the DAB in the peroxidase substrate medium. Specimens held in $70 \%$ ethanol overnight, in general, disclosed stronger and more consistent immunoreactivity than those not so treated. The immunocytochemical reaction in some but not other experiments appeared stronger in cryostat sections that had been treated with the detergent, Laboratory Aerosol prior to the immunobridge procedure. Increasing the concentration of DAB in the peroxidase substrate medium augmented electron opacity in reactive sites but appeared also to increase slightly non-specific background staining in restricted sites such as the basal plasmalemma and the cytoplasm immediately above the basal plasmamembrane in gastric epithelial cells neighbouring parietal cells.

The electron microscopical immunostaining corroborated that obtained by light microscopy (Fig. 1) and consistently showed selective reactivity for CA in the parietal cells of the stomach (Figs. 2-4). This staining contrasted with the complete lack of densification in other neighbouring cell types.

Within the parietal cells, electron opaque reaction product demonstrating the presence of carbonic anhydrase was observed in dense aggregates distributed throughout the cytoplasm (Figs. 2,3). This immunoreactivity was generally more concentrated in the basal hyaloplasm, particularly along the basal plasmalemma. Densification indicative of diffusion of enzyme or reaction product was also observed extending along the basal plasmalemma and basement membrane of adjacent zymogen or mucous cells.

The accumulation of electron-dense reaction product was observed in close association with the cytoplasmic face of cytoplasmic vesicles, along the outer membrane of mitochondria (Fig. 3) and in microvilli of the luminal surface and intracellular canaliculi. The microvilli observed in cross-section at high magnification disclosed marked densification on the plasmamembrane (Fig. 4). Nuclear profiles in parietal cells failed to stain. 

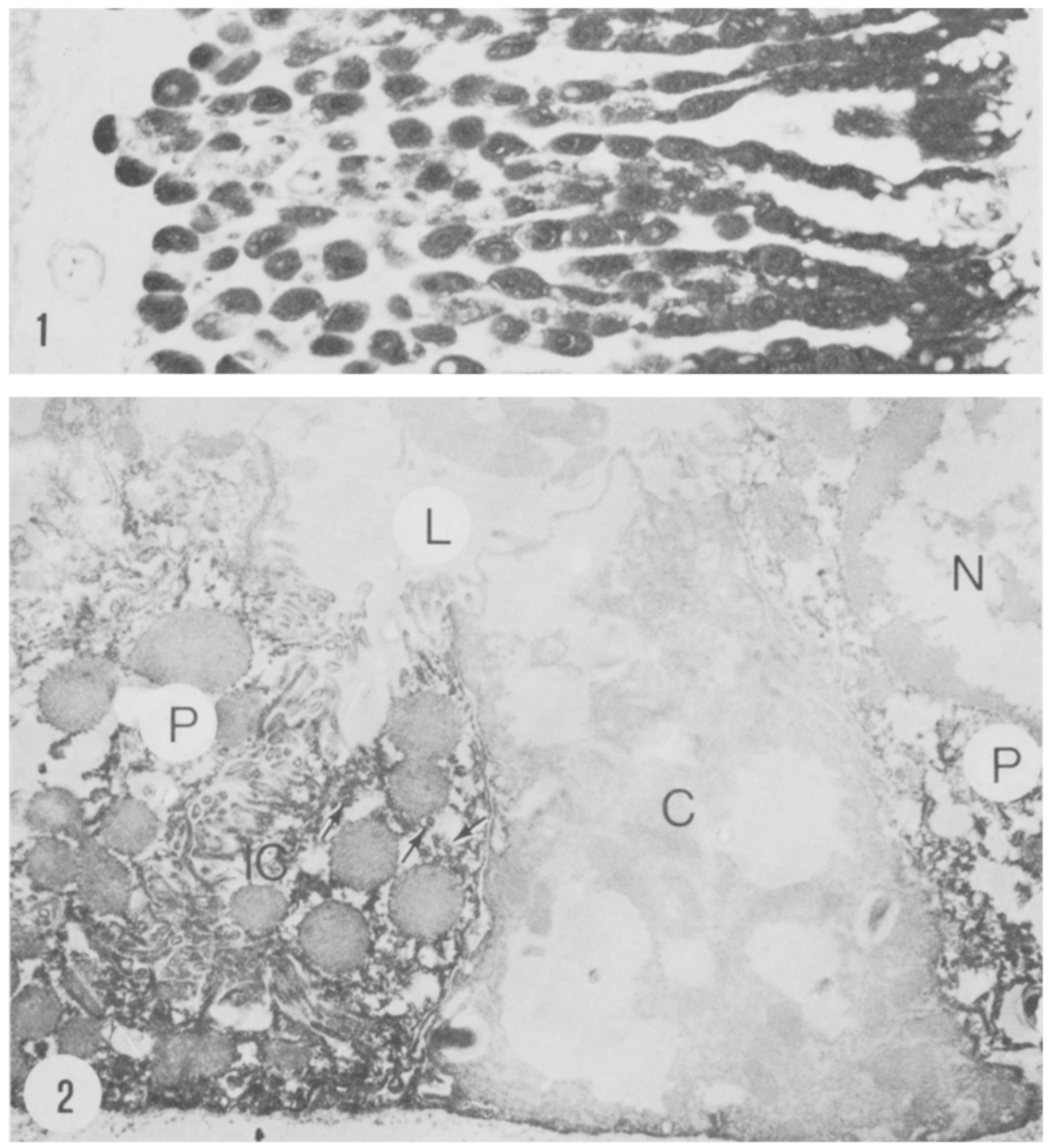

Fig. 1. In a paraffin section of guinea-pig stomach fixed with Carnoy's solution, carbonic anhydrase is located in parietal cells, which exceed other unreactive fundic cells in size and lie in a peripheral or demilunar position. Strong (brown) staining appears distributed throughout the cytoplasm of the parietal cells, whereas the lumen of intracellular canaliculi and nuclei lack reactivity. Surface epithelium at the right also reveals cytoplasmic immunostaining sparing the stored mucus. Immunoglobulin-peroxidase bridge procedure employing anti-carbonic anhydrase as the primary antiserum. $\times 275$.

Fig. 2. Heavily stained parietal cells (P) sandwich a completely unreactive chief cell (C). The peroxidase reaction product demonstrative of carbonic anhydrase fills the hyaloplasm of the 
Surface epithelial cells in some specimens disclosed moderate staining. In these cells densification was evident between the apical mucous droplets in a narrow stratum of apical cytoplasm (Fig. 5). This cytoplasmic density was inconstant, however.

No densification evidencing immunospecific reactivity was detected in control sections exposed initially to nonimmune rabbit serum in place of the anti-carbonic anhydrase sera (Figs. 6,7).

\section{Discussion}

The present study has demonstrated intracellular distribution of carbonic anhydrase by extending to the ultrastructural level an immunoglobulin peroxidase bridge method known to localize the enzyme specifically by light microscopy (Spicer et al., 1979).

Previous studies (Cross, 1970; Winborn et al., 1974) have undertaken to localize CA activity in parietal cells ultrastructurally using the cobalt capture technique. This method presumably depends on the reaction $\mathrm{H}_{2} \mathrm{CO}_{3} \rightleftarrows \mathrm{H}_{2} \mathrm{O}+\mathrm{CO}_{2}$, a reaction which is catalyzed by $\mathrm{CA}$ but can proceed rapidly without the enzyme and conceivably give rise to non-enzymatic deposits.

Gastric parietal cells are known to secrete $\mathrm{HCl}$. Although much is known about the biochemical basis for the acid production, the fine structural aspects of acid production and subsequent proton transport have not been clarified. ATPase has been implicated in supplying energy for active transport of electrolytes in gastric acid secretion (Durbin \& Kasbekar, 1965; Tormey, 1966; Sachs et al., 1968; Ernst, 1972). Carbonic anhydrase is also considered to play an integral part in acid secretion (Salganik et al., 1972; Narumi \& Kanno, 1973; Narumi \& Maki, 1973) through hydrating $\mathrm{CO}_{2}$ to provide $\mathrm{H}^{+}$and $\mathrm{HCO}_{3}^{-}$for participation in the secretion. The demonstration of bicarbonate-stimulated, thiocyanate-inhibited ATPase in mammalian (Sachs et al., 1972; Narumi \& Kanno, 1973) and amphibian (Kasbekar \& Durbin, 1965; Sachs et al., 1965) gastric mucosa suggests a further link between the CA-modulated system and active ion transport relevant to the acid secretion. The

parietal cells with stronger reactivity in the basal cytoplasm. Reaction product appears to be aggregated along the cytoplasmic face of the mitochondria (see Fig. 3), basolateral plasmalemma and microvilli protruding into the glandular lumen $(\mathrm{L})$ or intracellular canaliculus (IC) (see also Fig. 4). Densified small cytoplasmic vesicles (arrows) correspond with the vesicotubular system or smooth endoplasmic reticulum that appears prominent in routine morphological preparations of these cells. The nucleus $(\mathrm{N})$ is unstained. Densification attributable either to content of carbonic anhydrase in chief cells or to diffusion of the enzyme or reaction product is present along the basal plasmalemma and basal lamina of the chief cell. The procedure entailed paraformaldehyde fixation, cryosectioning, delipidization, treatment with 1\% Laboratory Aerosol and immunostaining for carbonic anhydrase without heavy metal counterstain. $\times 9800$. 

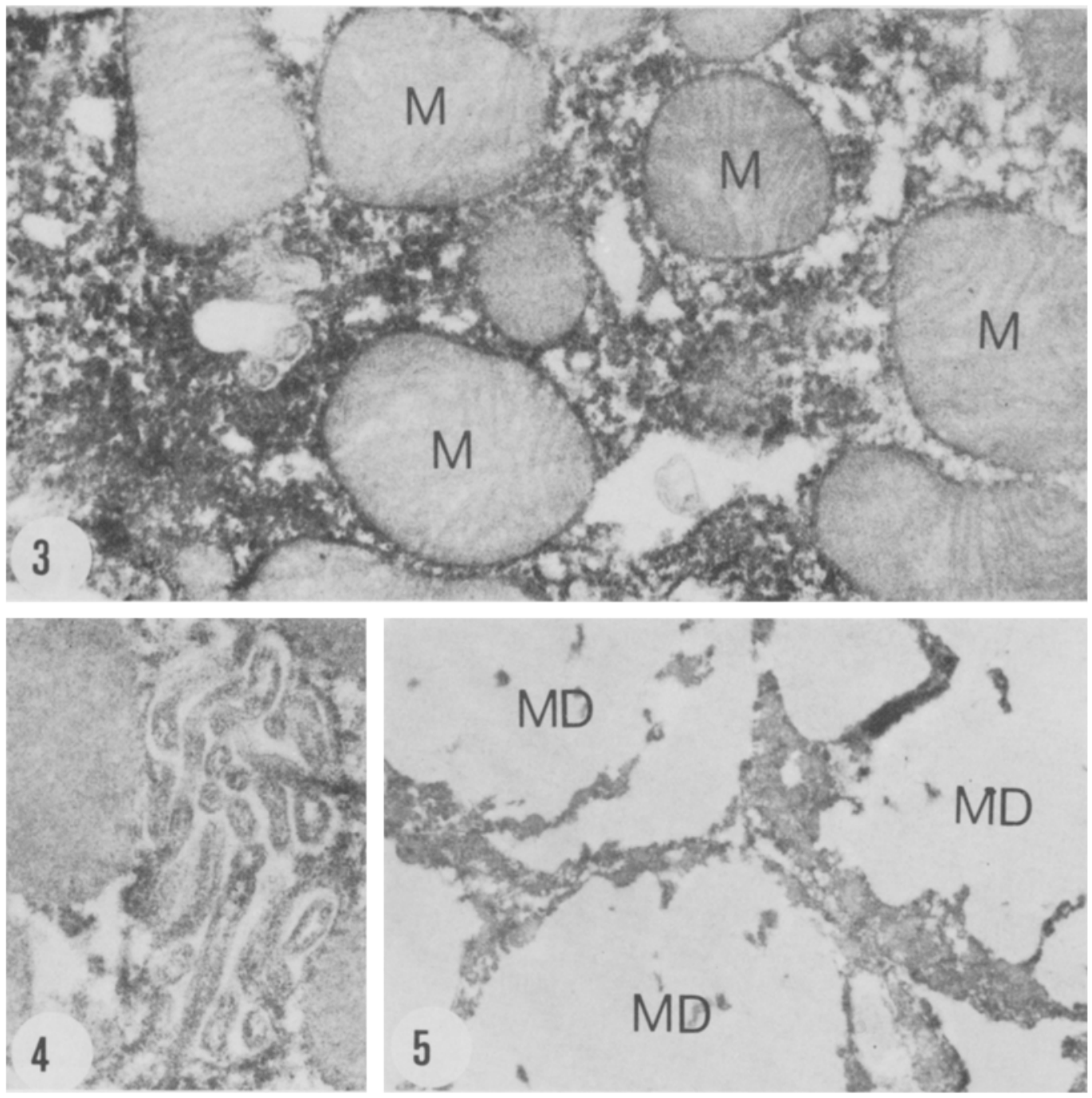

Fig. 3. As in Fig. 2 but at higher magnification illustrating more precisely electron-dense reaction product distributed throughout the cytoplasm and aggregated along the surface of the mitochondria (M). The matrix and cristae of mitochondria lack reactivity. Mitochondrial cristae are faintly visible here but were invisible in most formaldehyde fixed, immunostained specimens which were viewed without heavy metal counterstaining. $\times 30910$.

Fig. 4. Processed as for Fig. 2. Dense reaction product appears located at the plasmalemma but not in the core of the microvilli of an intracellular canaliculus. This density exceeds that at the same site in controls, whereas unstained cytoplasmic areas appear comparably dense in both preparations (cf. Fig. 7). The luminal aspect of the intracellular canaliculus lacks staining. $\times 33000$.

Fig. 5. Apical cytoplasm between unreactive mucous droplets (MD) in surface epithelial cells disclose moderate reaction product. This staining was not observed in some specimens. Processed as in Fig. 2 except for omission of delipidation step. $\times 10780$. 

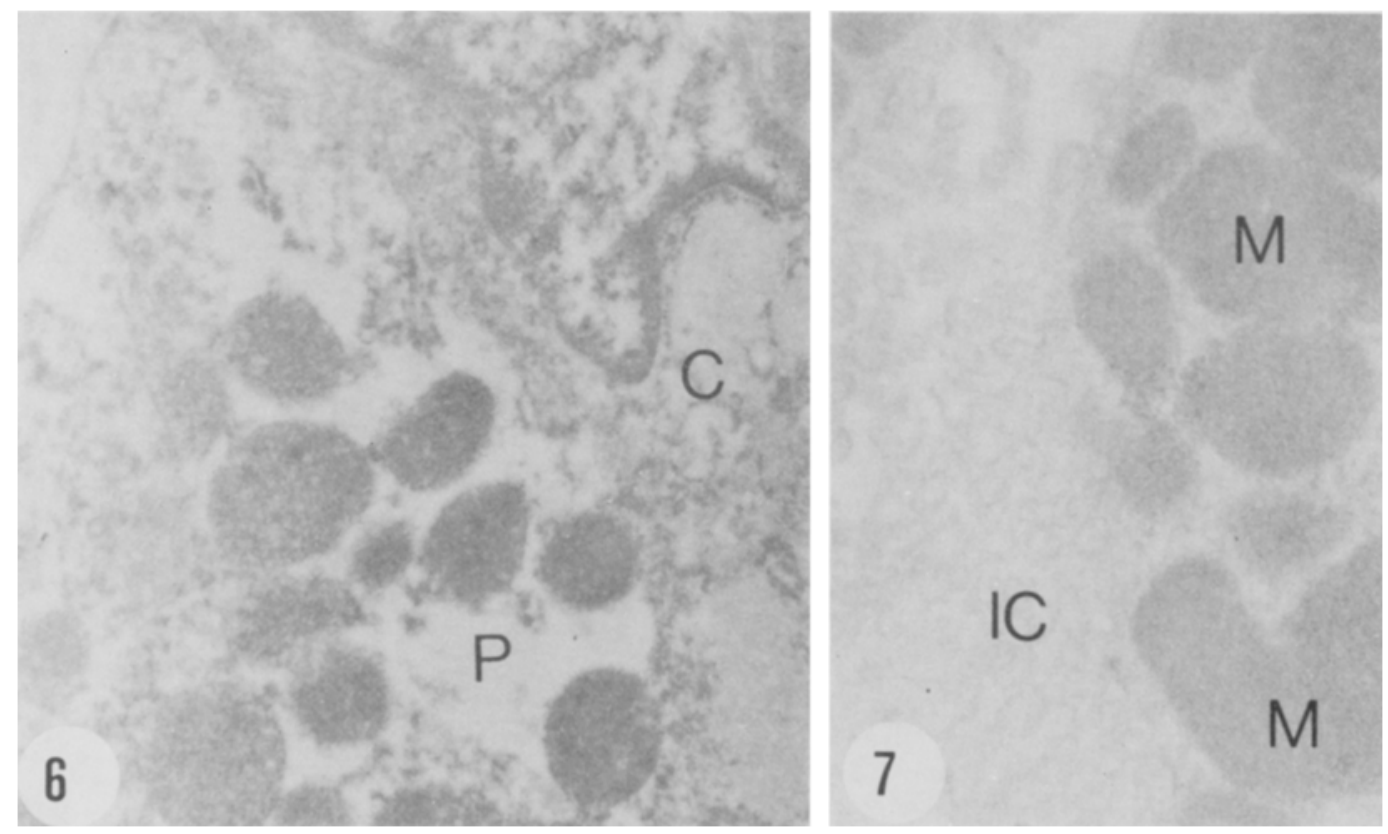

Fig. 6. Control section, adjacent to the immunostained sections processed as for Fig. 2 except for replacing the primary anti-carbonic anhydrase serum with normal rabbit serum in the immunoperoxidase bridge. The parietal cell (P) and neighbouring chief cell (C) lack staining (cf. Fig. 2). $\times 15400$.

Fig. 7. As in Fig. 6 showing in more detail the lack of staining in both the microvilli of the intracellular canaliculus (IC) and the surface of mitochondria (M) (cf. Figs, 3,4). $\times 30800$.

bicarbonate-stimulated ATPase was localized in both microsomal and mitochondrial fractions (Kasbekar \& Durbin, 1965; Sachs et al., 1965, 1972; Narumi \& Kanno, 1973 ) in density gradient fractionation of the gastric homogenate.

The present investigation evidences association of CA with intracellular canaliculi (Vollrath, 1959; Cross, 1977) and with cytoplasmic vesicle elements of the smooth endoplasmic reticulum. Since these vesicles represent morphologically the biochemical microsomal fraction thought to produce gastric acid, the enzyme appears strategically located for influencing proton concentration at the transport site. Carbonic anhydrase appeared from the immunocytochemistry to be distributed also throughout entire cytoplasm with denser concentration in the basal cytosol and at the basolateral plasmalemma. Biochemically $\mathrm{CA}$ has been considered to catalyze the hydration of $\mathrm{CO}_{2}$ to buffer the $\mathrm{OH}^{-}$resulting from proton secretion. The $\mathrm{HCO}_{3}^{-}$thus formed is secreted from the basolateral membrane to maintain the intracellular acid-base balance. In the latter case, the concentration of carbonic anhydrase in basal cytoplasm and at the basolateral plasmalemma of the parietal cell offers an advantage for the transport of bicarbonate to the intercellular space. Since carbonic anhydrase 
appears distributed throughout the cytosol, the increased enzyme concentration toward the basal cytoplasm and at the surface of mitochondria, cytoplasmic vesicles and plasmalemma possibly results from diffusion of enzyme during processing. It seems unlikely, however, that such diffusion could account for the consistently greater reactivity in the basal hyaloplasm.

\section{Acknowledgements}

The authors express their gratitude to Ms Betty Hall, Lorraine Anderson and Zandra McCormack for their expert technical assistance and to Mrs Dot Smith for secretarial assistance.

The research reported here was supported by NIH Grants AM-11028, AM-10956 and HL-19160.

\section{References}

CHURG, A. (1973) Carbonic anhydrase histochemistry: evidence for nonenzymatic reaction and artifact production. Histochemie 36, 293-302.

CROSS, S. A. M. (1970) Ultrastructural localisation of carbonic anhydrase in rat stomach parietal cells. Histochemie 22, 219-25.

CROSS, S. A. M. (1977) Localization of histamine and histamine $\mathrm{H}_{2}$-receptor antagonists in the gastric mucosa. Histochem. J. 9, 19-44.

DURBIN, R. P. \& KASBEKAR, D. K. (1965) Adenosine triphosphate and active transport by the stomach. Fed. Proc. 24, 1377-81.

ERNST, S. A. (1972) Transport adenosine triphosphatase cytochemistry. II. Cytochemical localization of ouabain-sensitive, potassium-dependent phosphatase activity in the secretory epithelium of the avian salt gland. J. Histochem. Cytochem. 20, 23-38.

GRAHAM, R. C. \& KARNOVSKY, M. J. (1966) The early stages of absorption of injected horseradish peroxidase in the proximal tubules of mouse kidney: Ultrastructural cytochemistry by a new technique. J. Histochem. Cytochem. 14, 291-302.

HANSSON, H, P. J. (1967) Histochemical demonstration of carbonic anhydrase activity. Histochemie 11, 112-28.

HÄUSSlER， G. (1958) Zur Technik und Spezifität des histochemischen Carboanhydrasenachweises im Modellversuch und in Gewebsschnitten von Rattennieren. Histochemie 1, 29-47.

KASBEKAR, D. K. \& DURBIN, R. P. (1965) An adenosine triphosphatase from frog gastric mucosa. Biochim. Biophys. Acta 105, 472-82.

MASON, T. E., PHIFER, R. F., SPICER, S. S., SWALLOW, R. A. \& DRESKIN, R. B. (1969) An immunoglobulin-enzyme bridge method for localizing tissue antigens. J. Histochem. Cytochem. 17, 563-9.

MUTHER, T. F. (1977) On the lack of specificity of the cobalt-bicarbonate method for carbonic anhydrase. J. Histochem. Cytochem. 25, 1043-50.

NARUMI, S. \& KANNO, M. (1973) Effects of gastric acid stimulants and inhibitors on the activities of $\mathrm{HCO}_{3}^{-}$-stimulated, $\mathrm{Mg}^{2+}$-dependent ATPase and carbonic anhydrase in rat gastric mucosa. Biochim. Biophys. Acta 311, 80-9.

NARUMI, S. \& MAKI, Y. (1973) Possible role of cyclic AMP in gastric acid secretion in rat. Activation of carbonic anhydrase. Biochim. Biophys. Acta 311, 90-7. 
Carbonic anhydrase in parietal cells

PHIFER, R. F., ORTH, D. N. \& SPICER, S. S. (1974) Specific demonstration of the human hypophyseal adrenocortico-melanotropic (ACTH/MSH) cell. J. clin. Endocrinol. Metab. 39, $684-92$.

SACHS, G., COLlieR, R. H., SHOEMAKER, R. L. \& HIRSCHOWITZ, B. I. (1968) The energy source for gastric $\mathrm{H}^{+}$secretion. Biochim. Biophys. Acta 162, 210-9.

SACHS, G., MITCH, W. E. \& HIRSCHOWITZ, B. I. (1965) Frog gastric mucosal ATPase. Proc. Soc. exp. Biol. Med. 119, 1023-7.

SACHS, G., SHAH, G., STRYCH, A., CLINE, G. \& HIRSCHOWITZ, B. I. (1972) Properties of ATPase of gastric mucosa. III. Distribution of $\mathrm{HCO}_{3}^{-}$-stimulated ATPase in gastric mucosa. Biochim. Biophys. Acta 266, 625-38.

SALGANIK, R. I., ARGUTINSKAYA, S. V. \& BERSIMBAEV, R. I. (1972) The stimulating action of gastric pentapeptide, histamine and cyclic adenosine $3^{\prime}, 5^{\prime}$-monophosphate on carbonic anhydrase in rat stomach. Experientia 28, 1190-1.

SPICER, S. S., FRAYSER, R., VIRELLA, G. \& HALL, B. J. (1977) Immunocytochemical localization of lysozymes in respiratory and other tissues. Lab. Invest. 36, 282-95.

SPICER, S. S., STOWARD, P. J. \& TASHIAN, R. E. (1979) The immunohistolocalization of carbonic anhydrase in rodent tissues. J. Histochem. Cytochem. 27, 820-31.

TORMEY, J. M. (1966) Significance of the histochemical demonstration of ATPase in epithelia noted for active transport. Nature, Lond. 210, 820-2.

VOLLRATH, L. (1959) Über Entwicklung und Funktion der Belegzellen der Magendrüsen. Z. Zellforsch. 50, 36-60.

WINBORN, W. B., SEELIG, L. L., JR \& GIRARD, C. M. (1974) Variation in the pattern of carbonic anhydrase activity in the cells of the gastric glands. Histochemistry 39, 289-300.

YOKOTA, S. (1969) Electron microscopic demonstration of carbonic anhydrase activity in mouse liver cells. Histochemie 19, 255-61. 